\title{
Application of Mobile learning in College English Teaching
}

\author{
Xiuhuan Ma \\ Public English Department, Liaoning University of International Business and Economics, Dalian, \\ 116052, China \\ 365556037@qq.com
}

Keywords: mobile learning; English teaching; feasibility analysis; application strategy

\begin{abstract}
Mobile learning is in recent years the rise of a new learning model, based on wireless network and mobile terminals, mobility, interactivity, across time and space, virtual and flooding in the sexual characteristics. Aiming at the problems of traditional English teaching, this passage studies the application of mobile learning in college English teaching. The research content includes three aspects: the feasibility analysis of mobile learning college English teaching, mobile learning mode of college English teaching, the application of mobile learning in college English learning strategies. The use of this research, is helpful to stimulate learners' interest in learning English, strengthen the ability of autonomic learning, improve the comprehensive application ability, improve college English teaching.
\end{abstract}

\section{Introduction}

M-learning is a modern mobile communication technology and mobile learning theory combined with the emergence of a new form of learning. Learners can at any time and any place, use of wireless mobile communication technology, wireless mobile communications equipment and wireless communications networks, education information, education resources and education services, communicate with others, learn form of a new type of learning. Mobile learning changed people's form, that is, by formal learning extends to the informal learning, provides a new lifelong learning in the form [1, 2]. Mobile learning has the following characteristics: mobility, the use of wireless mobile terminal equipment, audio, video, data and other information acquisition and learning; Interactive, learners in autonomous learning at the same time, can with peers and teachers question discussion and communication; Across time and space, students' learning is not limited by time and place, teachers can also keep the demands of the teaching resources and posted on the Internet; Virtual sex, can dynamically set up virtual schools, classes and virtual teachers, the relationship between students and teachers can virtual; Personalized, learners can be according to actual situation to learn at their own pace, learning time, place and learning content; In the sex, the types of mobile devices and functions more and more, the price is cheaper and cheaper, more and more the number of people owning mobile devices.

English is one of the most common language in the world, learning English well helps to exchange and cooperation with the people of the world. Since China's accession to the WTO, every field constantly with the world, the future requirements for talents of foreign language ability is higher and higher."College English curriculum requirements", points out that the institutions of higher learning should make full use of modern information technology, based on the computer and the classroom English teaching mode, the improvement is given priority to with teachers' teaching of the single teaching mode. New teaching model should be to modern information technology, especially network technology as the support, can make the teaching and learning of English in a certain extent, not limited by time and place, the direction of individualized and autonomous learning. To carry out mobile learning in college English teaching in order to establish student-centered, self control learning progress, personalized learning way to explore a new way. Learners can get anywhere, anytime and illustrated, the combination of dynamic and static resource, to arouse learners' interest in learning English at the university of, enhance the ability of autonomic learning, to strengthen college students' English listening ability, improve college students' English comprehensive application ability, to increase competitiveness in the increasingly competitive 
society, college students but also to improve college English teaching.

\section{Feasibility Analysis of Mobile Learning Application in College English Teaching}

As mobile learning theory in each application in the field of teaching, more and more researchers and educators to explore the feasibility of mobile learning in English language teaching application. Base on the research results by predecessors and in combination with the authors years of experience in English teaching, use the mobile learning apply to college English teaching are summarized as follows [3-5] :

(1) Education technology application in English teaching has a long history. In the late $1950 \mathrm{~s}$, began to use English phonetics teaching laboratory heard that teaching method, and ratified. With the development of computer technology, in the $1970 \mathrm{~s}$, focusing on the training of the computer aided teaching English began to appear and rapid development of widely used. Developed in the $1990 \mathrm{~s}$, the network aided English teaching, and form a kind of new learning concept. Entering the new century, the mobile wireless network coverage gradually wide, technology improvement, and fees have mobile communication equipment, fast into the mass consumer domain, mobile learning English become possible. Mobile learning was applied to English teaching, the teaching method and the computer and network assisted English teaching after another technology combined with the language of the new teaching mode, has a certain historical continuity.

(2) The rich theoretical support provides guidance for practical applications. Constructivism theory is that knowledge is not entirely by teachers to teach, but learners in certain social cultural background, with the help of others' help, using the necessary learning materials, through constructing way; Learning style theory suggests that different people have different ways of learning, to understand their own learning style is beneficial to improve learning efficiency. Because the learners have different intelligence factors and learning styles, only in line with the intelligence factors and learning styles of learning style is the most suitable way; Dialogue learning theory for recognition, under the support of mobile technology, dialogue can extend from inside the classroom to classroom external, from books to actual life. In the mobile learning system, under the support of dialogue and interaction in everyday life more abundant. Due to the updating and development of mobile technology, also further rich dialogue way and way, can achieve more effective session.

(3) Mobile learning combined with English teaching, and will move to form a unique English teaching mode. In the traditional school education, English teaching mainly embodied in a formal classroom teaching. Due to the evolution of the English teachers' teaching concept, now most pay attention to communication and interaction, language class atmosphere was active, students participation is high. However, teachers of English outside of class for English teaching approaches and without use of space and time. Mobile learning the effective application of just can make up for the defect .Mobile learning helps English teachers with language skills, language and culture background relevant to the topics covered in the content such as teach students after class, so that the mobile learning to be the supplement and extension of classroom interaction. Can move at the same time, the language teaching to meet the needs of the student to the flexible learning, stimulates the student to the language learning more widely participation, and to encourage informal learning.

(4) The English mobile learning resources gradually rich create conditions for mobile learning. With the development of mobile learning trend, English mobile learning resources is becoming more and more rich. Many colleges and universities have conducted research about "English mobile learning", and formed abundant subject results repository, including courseware, text, data, video, etc., these resources characteristic is short, built around a certain theme, is suitable for the scattered students in extra-curricular time to learn. Will these resources uploaded to air classroom or online learning system, students can freely download or online watch.

\section{Mobile Learning Mode of College English Teaching}

Teaching mode is in a certain education ideology, teaching theory, under the guidance of learning 
theory, under certain conditions the stability of the structure in the teaching activity process, is a system of methodology to carry out teaching activities, is based on the theory of a certain teaching and set up the framework of a relatively stable teaching activities and programs. Teaching mode is the embodiment of teaching theory, but also directly to and guide the teaching practice, operable, is a bridge between teaching theory and teaching practice. One of the goals of teaching model reform is to promote the formation of students' individualized learning methods and the development of students' autonomous learning ability. New teaching model should be able to make students choose is suitable for the materials and methods to study, they need to get the guidance of learning strategy, gradually improve their autonomous learning ability. New English teaching mode to the student-centered, not only teach language knowledge and skills, pay more attention to develop language application ability and autonomous learning ability of changing thought and practice of teaching, to cultivate the students' lifelong learning ability as the guidance of lifelong education.

College English teaching aims to improve students' English communicative ability, mainly includes four aspects: grammatical ability, namely with English vocabulary, grammar, semantics and sound system related knowledge; Social linguistics, refers to the English and the knowledge of the relationship between nonverbal environment [6]. Learners need to know, for example, in the different situations of different speakers should adopt what appellation form, etc.; Discourse ability, is should know how to start a conversation, how to end the conversation. Strategy ability, namely the related knowledge of communication strategy. For a long time, the traditional college English teaching model too much emphasis on the cultivation of student's ability of grammar, and ignore other aspects ability., therefore, must change the "teacher-centered" teaching model, and the new teaching mode can fully embody the teachers in a dominant position in the process of teaching, and to be able to fully exert the principal role of students' learning. Only in this way, the new teaching mode can cultivate the students' English communicative competence comprehensively. Based on mobile learning of college English teaching mode is shown in Fig.1.
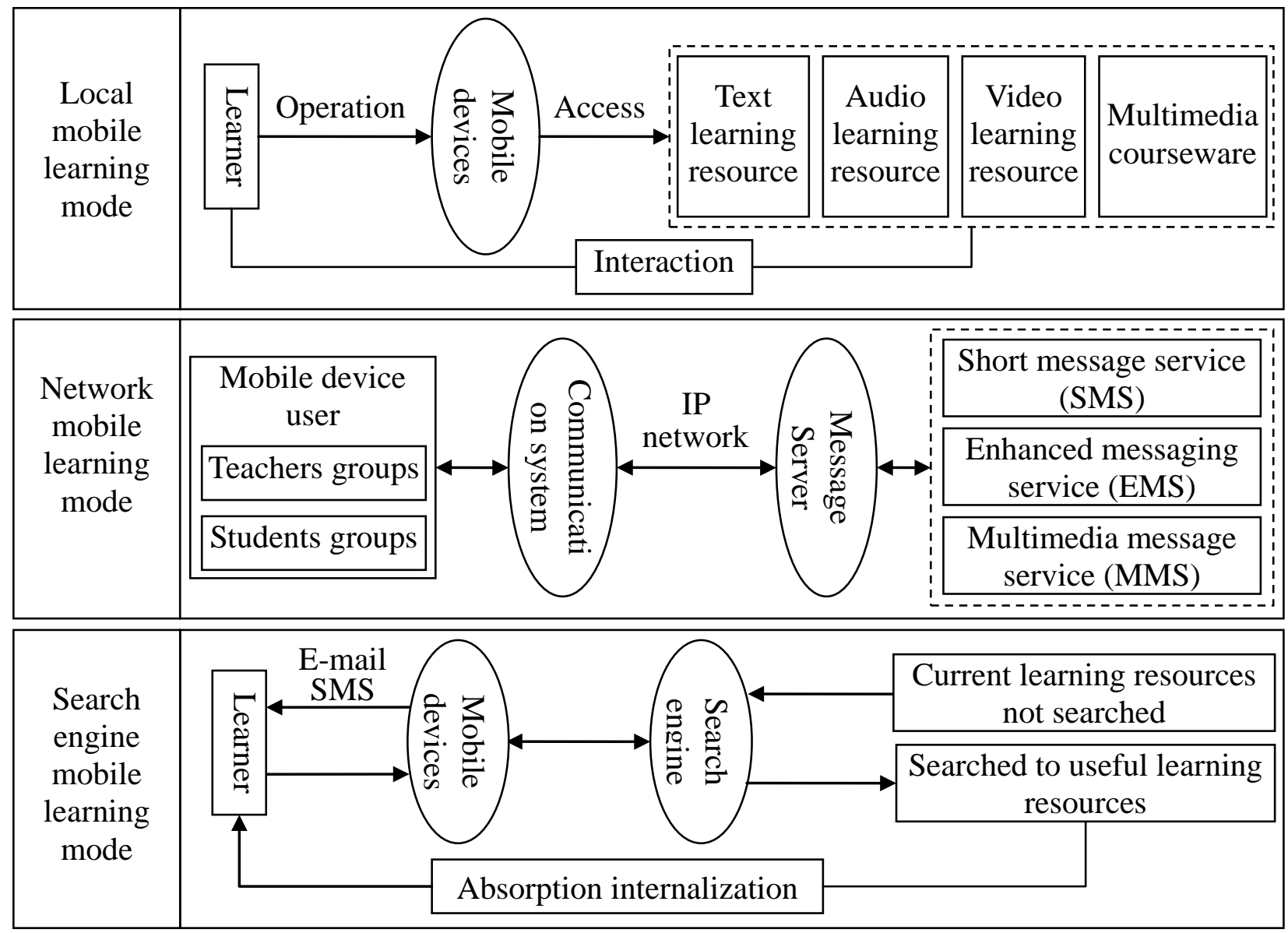

Fig. 1. Mobile learning mode 


\section{Application Strategy on Mobile Learning in College English Teaching}

Learning through mobile phones or other mobile devices, more freedom, than in the traditional sense of the study has certain superiority, but for the students' autonomous learning ability and self-control ability with higher requirements. Therefore, mobile learning must develop corresponding autonomous learning teaching strategies, to stimulate students' interest in learning and creativity, improve the students' autonomous learning ability, lets the student was in a state of positive good learning. This article formulated strategies as follows [7-9]:

(1) To improve the teaching content to adapt mobile learning. Using modern information technology and Internet technology students like psychology, encourage students to use mobile communication equipment online learning English, use English learning software anytime, anywhere access to new knowledge. Out of the traditional teachers tell students learn, English learning content extension to the outside of the classroom, lets the student feel the British and American culture, British and American culture, really fall in love with English, change passive learning into active learning. Teachers collect classic English original movie relevant to the subject matter and materials, students will download movies to mobile devices, using a large number of fragments after class time, watching a movie while learning English, experience the fun of mobile learning mode. At the same time, the teacher in advance from the movie content, character, cultural differences in design problem, give tips, guides the student to discuss, so to training understanding ability and strengthen the power of expression, implementation from self-study, discussion to practice the whole process of learning.

(2) Construction is suitable for mobile learning English resources. A lot of English learning resources on the network, but different ways of mobile terminal for resources present different requirements, users of mobile terminal flow under different levels, really suitable for mobile terminals of English learning resources are limited. Increased utilization of learning, in order to cooperate with mobile terminal construction should be guided by the principle of generality of learning resources: consider the learners' interest and learning motivation, to attract the learners, and make the learners to think deeply about; Mobile learning is a personalized approach to learning, learning resources should consider habits and levels of learners, try to make each learner can according to oneself to like and learning habits and ways; Mobile learning is autonomous learning mode, interactivity is also very strong, the design of mobile learning resources can play to the learners' autonomous learning ability, and can strengthen the cooperative learning; In mobile learning, learners to develop autonomous learning ability, resources designers should have the teaching goal quantification, allow students to test whether to reach the target.

(3) To prevent the vocabulary and grammar learning marginalized. When students use the move tool for learning English become a habit, after this the habit of listening to English, read English and speak English will become an indispensable part of daily life. Learners at any time, any place, as long as want to learn, can be absorbed in to realize mobile learning, in the mobile hear English, read English. But, in the process of mobile learning English, to avoid the tendency of English vocabulary, grammar, marginalized, listening to English materials, more don't understand the word meaning, does not understand its meaning, it is hard to understand. In this case, will use the move tool electronic dictionary, query word meaning, network of query word meaning. Online learning, learning the collocation of words, grammar and pronunciation, etc., and make detailed records on important learning points, will be unfamiliar learning knowledge and skills in the first place, it can quickly into a new thinking learning state.

(4) The monitoring system of the mobile learning English. Including three aspects, one is the focus on students' emotion. Teachers through the design review, asking questions, discussion and other activities to strengthen students discontinuous, decentralized, fuzzy knowledge, help to summarize and improve, improve the original knowledge structure, create conditions for mobile learning .Stimulating students' potential, timely encouragement and humanistic care for the students to create a safe learning environment emotion; The second is to strengthen process monitoring. Students to adapt to mobile learning English needs a process, the teacher must overcome the fear, and make the necessary on-site guidance, the implementation of the necessary inspection and test, 
to help students overcome step by step for mobile learning English does not adapt, accumulating experience, continuous development and progress;3 it is the answer in a timely manner. English a lot of questions that exist in the mobile learning, if can't get the answer in time, will affect the mobile students in English learning enthusiasm. Can make electronic question-answering system, between the teachers and students, students can use the QQ, Weibo release and email message, question and answer each other and improve together.

\section{Conclusion}

Mobile learning is based on the wireless and mobile communication network technology and equipment, can be anywhere at any time to provide a rich and effective learning content, and meet the needs of learners and communication between teachers and students between a kind of new learning style. The research content of this article is of great significance to promote the college English teaching. Mobile learning is still in its infancy, however, need to intensify policy support, education departments at all levels to recognize the importance of mobile learning, that is, this is a new generation of the inevitable trend in the application of education technology, should increase investment in human, material and financial resources [10,11]. To guide teachers and students to set up the concept of mobile learning, especially the teacher's guide to strengthen, which requires teachers transformation idea. At the same time, also must guide the student to form the habit of mobile learning, keep the mobile learning interest, increase trust in mobile learning. 


\section{References}

[1] R. Y. Pan, "Developing the Sustainable Ability of English Learning for College Students In the Mobile Learning Environment," Yinshan Academic Journal, vol. 27, no. 2, pp. 19-23, 2014.

[2] Bernardo Tabuenca, Marco Kalz, Hendrik Drachsler, Marcus Specht, "Time will tell: The role of mobile learning analytics in self-regulated learning," Computers \& Education, vol. 89, no. 11, pp. 53-74, 2015.

[3] F. Wu, "Research on mobile learning in college English teaching," Industrial \& Science Tribune, vol. 10, no. 6, pp. 122-124, 2011.

[4] Z. Z. Shen, "A Study on Internet-based English Mobile Learning," Journal of Nantong Vocational \& Technical Shipping College, vol. 11, no. 3, pp. 126-128, 2012.

[5] L. H. Xiao, "English teaching mode in the theory of mobile learning," Journal of Shenyang Normal University(Social Science Edition), vol. 37, no. 3, pp. 184-186, 2013.

[6] S. B. Bao, "M-Learning Combined Teaching Model of College English," Research and Exploration in Laboratory, vol. 32, no. 4, pp. 144-151, 2013.

[7] Y. Wei, M. D. Liu, "New Transition: On college English Teaching in M-learning," Journal of Hunan First Normal University, vol. 15, no. 2, pp. 48-51, 2015.

[8] K. Lv, "M-learning in College English Teaching," Journal of Qiqihar Junior Teachers' College, vol. 22, no. 6, pp. 99-100, 2012.

[9] J. Li, "On the Feasibility of College English Mobile Learning in West China: Taking Guangxi University as an example," Journal of Guilin Normal College, vol. 28, no. 1, pp. 129-132, 2014.

[10] J. Q. Xue, "Research on construction and development of m-learning mode of College English," Experimental Technology and Management, vol. 31, no. 3, pp. 176-179, 2014.

[11] J. Hu, "Application of 1VIobile Learning to College English Teaching Based on Flipped Classroom Teaching 1VIodel," Journal of Hubei University of Education, vol. 32, no. 3, pp. 100-103, 2015. 